University of Wollongong

Research Online

Faculty of Engineering and Information

Faculty of Engineering and Information

Sciences - Papers: Part B

Sciences

2017

\title{
A basis for comparing progressive collapse resistance of moment frames and connections
}

Ling Li

Tongji University, University of Wollongong

Wei Wang

Tongji University

Yiyi Chen

Tongji University

Lip H. Teh

University of Wollongong, Iteh@uow.edu.au

Follow this and additional works at: https://ro.uow.edu.au/eispapers1

Part of the Engineering Commons, and the Science and Technology Studies Commons

Research Online is the open access institutional repository for the University of Wollongong. For further information contact the UOW Library: research-pubs@uow.edu.au 


\title{
A basis for comparing progressive collapse resistance of moment frames and connections
}

\begin{abstract}
The progressive collapse resistance of a moment frame in the event of an inner column loss has been studied in terms of either the beam span or the beam span-to-depth ratio. This study reiterates that, strictly speaking, it is the beam span-to-depth ratio that is the underlying factor. Basically the larger the span-to-depth ratio, the better the progressive collapse resistance if the beams have been similarly optimised against plastic hinging under the design floor load. In comparing the performance of various types of steel double-span assemblies against each other, it would not always be appropriate to normalize their resistance against the same uniformly distributed load on the floors unless the beams have been similarly optimised. This article explains how the progressive collapse resistance of various types of steel double-span assemblies can be clearly compared against each other with respect to their development of the catenary mechanism, independently of the optimisation extent of the beam section against plastic hinging under the design floor load. The quasi-static resistance is normalized against the plastic hinge load, and the chord rotation is normalized against the plastic rotation. The proposed procedure further enables a rigorous comparison between different types of steel moment connections since the effects of different beam sections and different spans are filtered out under the same span-todepth ratio. Issues such as the dynamic effects of sudden column loss, the contributory effects of floor slabs and the second-order effects of topological changes are not relevant to the present study.

\section{Disciplines}

Engineering | Science and Technology Studies

\section{Publication Details}

Li, L., Wang, W., Chen, Y. \& Teh, L. H. (2017). A basis for comparing progressive collapse resistance of moment frames and connections. Journal of Constructional Steel Research, 139 1-5.
\end{abstract}


A Basis for Comparing Progressive Collapse Resistance of Moment Frames and Connections

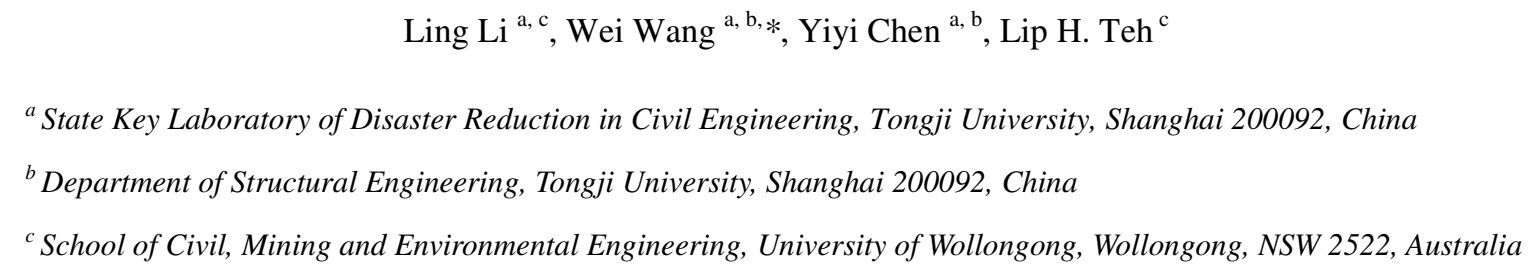

Abstract: The progressive collapse resistance of a moment frame in the event of an inner column loss has been studied in terms of either the beam span or the beam span-to-depth ratio. This study reiterates that, strictly speaking, it is the beam span-to-depth ratio that is the underlying factor. Basically the larger the span-to-depth ratio, the better the progressive collapse resistance if the beams have been similarly optimised against plastic hinging under the design floor load. In comparing the performance of various types of steel double-span assemblies against each other, it would not always be appropriate to normalize their resistance against the same uniformly distributed load on the floors unless the beams have been similarly optimised. This article explains how the progressive collapse resistance of various types of steel double-span assemblies can be clearly compared against each other with respect to their development of the catenary mechanism, independently of the optimisation extent of the beam section against plastic hinging under the design floor load. The quasi-static resistance is normalized against the plastic hinge load, and the chord rotation is normalized against the plastic rotation. The proposed procedure further enables a rigorous comparison between different types of steel moment connections since the effects of different beam sections and different spans are filtered out under the same span-to-depth ratio. Issues such as the dynamic effects of sudden column loss, the contributory effects of floor slabs and the second-order effects of topological changes are not relevant to the present study.

Keywords: progressive collapse; double-span assembly; span-to-depth ratio; vertical resistance; catenary mechanism.

* Corresponding author. Tel.: +86-21-65982926; Fax: +86-21-65984976.

Email address: weiwang@tongji.edu.cn (W. Wang) 


\section{Introduction}

In the literature of progressive collapse prevention, the Alternate Path (AP) method is

widely used to examine the surviving structural capacity following a vertical load-carrying element loss $[1,2]$. In order to prevent the initial damage from spreading to the surrounding areas in a frame system, the remaining structure within the damaged bays should be able to bridge over the lost column. When an inner column is removed from the frame, the load-carrying capacity of the double-span assembly above the removed column plays a crucial role in the progressive collapse prevention. In the simplified framework for multi-storey buildings proposed by Izzuddin et al. [3], the double-span beam-column assembly within the damage bays is deemed as the lowest level of the structure among the various levels of sub-structure idealisation, and its response is used for composing the higher level sub-structures. The performance of the double-span assembly has been found through experimental study [4-9] to primarily depend on the beam section as well as the beam-to-column connection configuration in developing the flexural and the catenary mechanisms to carry the load previously supported by the damaged (removed) column.

Since the catenary mechanism involves the development of axial forces in the beams as the double-span assembly deflects downwards, the beam span $l_{0}$ has been identified to be another important factor [10-12]. However, the effect of the beam span on the performance of the double-span assembly has not been explained very thoroughly, and this technical note will show that comparisons on the basis of the beam span alone can sometimes be ambiguous or even misleading unless the context is defined clearly.

In the literature, the bridging capacities of different beam spans are often simply 
evaluated in terms of the vertical load resistance and the corresponding vertical translation of the damaged inner column, which were actually due to the combined effects of the beam section and the beam span [13]. In fact, Weigand \& Berman [11] have stated that even the use of connection rotations would not be sufficient to objectively compare the performance of connections between double-span assemblies of varying spans.

In order to compare the performance of various types of steel double-span assemblies with respect to their development of the catenary mechanism in a straightforward manner, this technical note will propose an evaluation procedure that is independent of the optimisation extent of the beam section against plastic hinging under the design floor load.

The premise of the procedure is that, in order to compare the performance of various types of double-span assemblies and objectively assess the integrity of the steel beam-to-column connections, all the beams should have been similarly optimised against plastic hinging under the design floor load. The robustness of the proposed procedure will be demonstrated through numerical examples. Issues such as the dynamic effects of sudden topological changes are not relevant to the present study.

\section{Identification of the first problem} designed steel moment resisting frames were investigated by Rezvani et al. [10] using three frames having different beam spans $l_{0}$ but similar beam span-to-depth ratios $R$. The design details of the three frames are shown in Table 1 and Fig. 1. The steel 
elements. The variable $W_{\mathrm{p}}$ in Table 1 denotes the plastic section modulus. It should be noted that the span-to-depth ratios of the three frames are not significantly different from each other.

In the pushdown analysis by Rezvani et al. [10], the uniformly distributed load on the beams in the damaged bays was proportionally increased in a quasi-static manner, and it was found that the vertical resistance of the studied frames increased as the beam span decreased, as implied by Fig. 2. The pushdown analysis results of the three frames were interpreted using a load factor $\zeta_{1}$, which is the ratio of the applied load in the damaged bays to its reference load computed from a given uniformly distributed load $q_{0}$ on the floor and the beam span $l_{0}$, and the vertical displacement of the top of the removed column $\delta$.

Table 1. Primary design parameters of frames in the pushdown analyses of Rezvani et al. [10].

\begin{tabular}{ccccccc}
\hline $\begin{array}{c}\text { Frame and case } \\
\text { labels }\end{array}$ & $\begin{array}{c}\text { Beam span } \\
l_{0 i^{*}}\end{array}$ & $\begin{array}{c}\text { Beam section } \\
\text { of the first two storeys }\end{array}$ & $\begin{array}{c}\text { Span-to-depth } \\
\text { ratio } R_{\mathrm{i}}\end{array}$ & $\alpha_{i}=l_{0 i} / l_{02}$ & $\beta_{\mathrm{i}}=W_{\mathrm{p} i} / W_{\mathrm{p} 2}$ & $\alpha_{i}^{3} / \beta_{i}$ \\
\hline Frame 1 (Case2) & $4 \mathrm{~m}$ & IPE360, $W_{\mathrm{p} 1}=1.02 \times 10^{6} \mathrm{~mm}^{3}$ & 11.1 & 0.667 & 0.434 & 1.486 \\
Frame 2 (Case4) & $6 \mathrm{~m}$ & IPE500, $W_{\mathrm{p} 2}=2.20 \times 10^{6} \mathrm{~mm}^{3}$ & 12.0 & 1.000 & 1.000 & 1.000 \\
Frame 3 (Case6) & $8 \mathrm{~m}$ & IPE600, $W_{\mathrm{p} 3}=3.51 \times 10^{6} \mathrm{~mm}^{3}$ & 13.3 & 1.333 & 1.596 & 0.925 \\
\hline
\end{tabular}

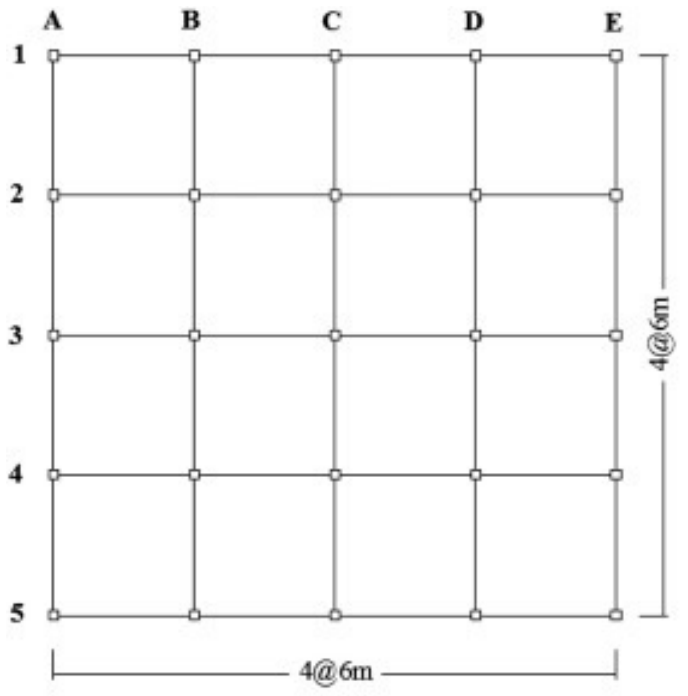

(a) Plan view.

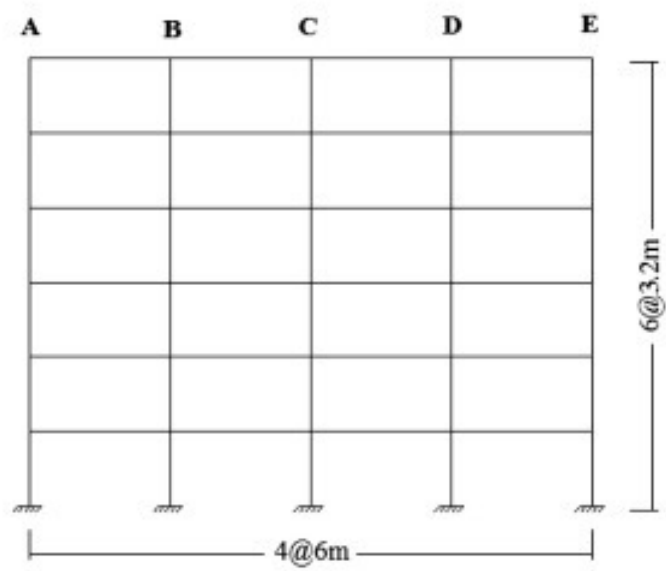

(b) Elevation View.

Fig. 1. Topology of one studied frame having the beam span of $6.0 \mathrm{~m}$ [10]. 


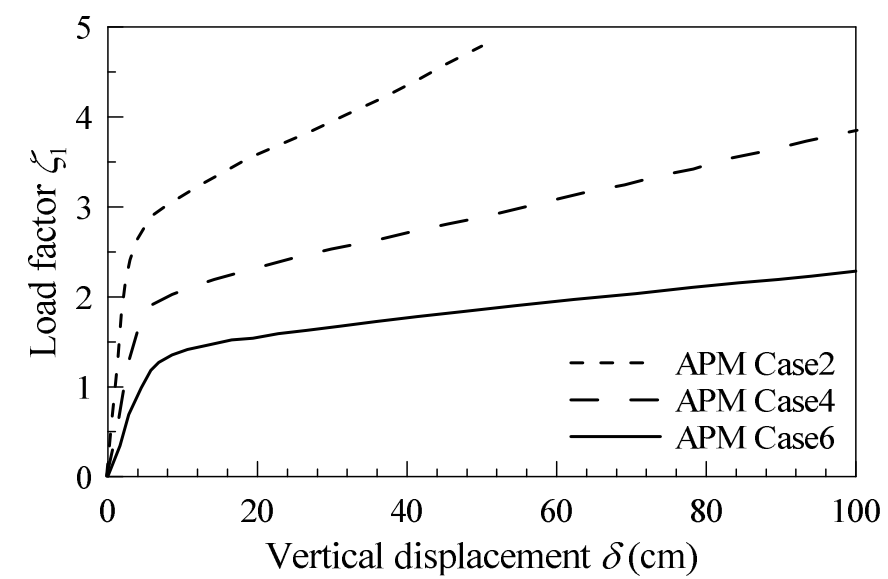

Fig. 2. Pushdown analysis results of frames having different spans [10].

The increased load factor $\zeta_{1}$ at a given vertical displacement of the smaller span assembly can be attributed to the larger chord rotation of its shorter beams and the way the load factor $\zeta_{1}$ has been calculated. The latter also affects the apparent progressive collapse strength of the assembly shown in Fig. 2. The load factor $\zeta_{1}$ of the three frames was computed using the same uniformly distributed load $q_{0}$ on the floor, which would be objective only if the beams had been similarly optimised against plastic hinging under the governing design load combination (whether the normal or the seismic load). However, it is not entirely clear whether this condition holds in the case study of Rezvani et al. [10] as the plastic section modulus $W_{\mathrm{p}}$ of the smallest span given in Table 1 appears to be somewhat large relative to that of the largest span if both are to be optimised against plastic hinging (whether under the normal design load or under the seismic load), perhaps due to the discrete availability of the beam sections in practice where the difference in plastic section moduli between one beam section and the next satisfactory size may be significantly higher than that required by the theoretical design. The finding by Rezvani et al. [10] that decreasing the span by half led to $91 \%$ increase in the progressive collapse strength should therefore be interpreted with caution since it does not appear to be general. 


\section{Resolution of the first problem}

The yield strength $f_{\mathrm{y}}$ is the same for all three frames analysed by Rezvani et al. [10].

In order to compare the performance of various types of steel double-span assemblies against each other independently of the optimisation extent of the beams against plastic hinging under the design floor load, the quasi-static load $F$ is normalized as

$$
\frac{F}{F_{\mathrm{p}}}=\frac{\zeta_{1} \zeta_{2} q_{0} l_{0}{ }^{2}}{4 W_{\mathrm{p}} f_{\mathrm{y}} / l_{0}}=\zeta_{1} \frac{l_{0}{ }^{3}}{W_{\mathrm{p}}} \frac{\zeta_{2} q_{0}}{4 f_{\mathrm{y}}}=\zeta_{1} \eta_{1} \eta_{2}
$$

It should be noted that, in terms of comparing the progressive collapse resistance of various types of steel double-span assemblies, normalizing the load $F$ against the respective plastic hinge load $F_{\mathrm{p}}$ is equivalent to normalizing the former against the design floor load for which the beams have been optimised.

The distribution factor $\zeta_{2}$ is not provided by Rezvani et al. [10], but Appendix A shows how a comparison between their three frames on the basis of Equation (3) can still 
be conducted using the load factors $\zeta_{1}$ plotted in Fig. 2.

Consistent with the approach of Lee et al. [13], the chord rotation is selected to be the deformation parameter of the steel double-span assembly:

$$
(\theta)_{i}=\frac{(\delta)_{i}}{l_{0 i}}, \quad i=1,2,3
$$

Figure 3, which makes use of Equations (A2) and (4), reinterprets the pushdown analysis results of Rezvani et al. shown in Fig. 2. The present reinterpretation indicates that the resistance developments of the three steel double-span assemblies, which had rather similar span-to-depth ratios as evident from Table 1, are consistent with each other.

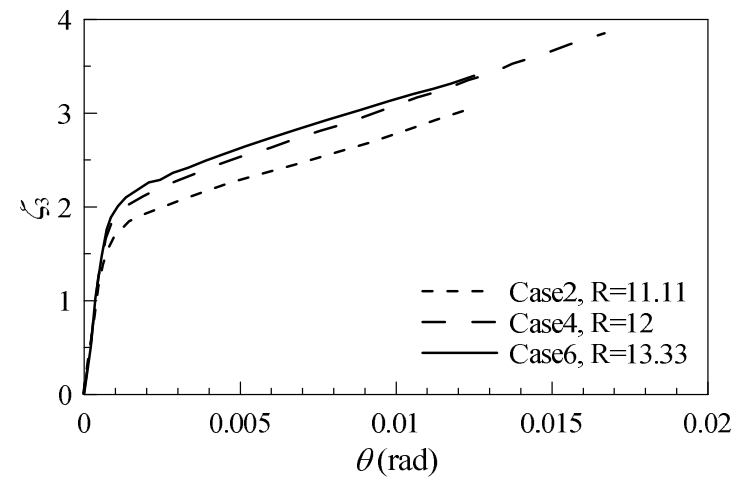

Fig. 3. Re-interpreted pushdown analysis results of Rezvani et al. [10].

\section{Effect of the beam span-to-depth ratio}

In order to ascertain the effects of the beam span-to-depth ratio, two sets of pushdown analyses were conducted in the present work using ABAQUS [14]. Each set has three steel double-span assemblies made of steel Q345 with span-to-depth ratios of 5, 10 and 15, respectively. In the first set, all the beams are composed of the same I-section H300 $\times 150 \times 6 \times 8$ configured with square hollow section $($ SHS) column of SHS $250 \times 14$. In the second set, the three assemblies are composed of $\mathrm{H} 300 \times 150 \times 6 \times 8, \mathrm{H} 400 \times 200 \times 7 \times 11$

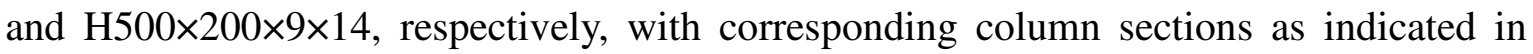


Table 2. Beam and column sections of the steel double-span assemblies in the second set.

\begin{tabular}{ccc}
\hline Span-to-depth ratio & Beam section & Column section \\
\hline 5 & $\mathrm{H} 300 \times 150 \times 6 \times 8$ & SHS $250 \times 14$ \\
10 & $\mathrm{H} 400 \times 200 \times 7 \times 11$ & SHS $300 \times 16$ \\
15 & $\mathrm{H} 500 \times 200 \times 9 \times 14$ & SHS $400 \times 16$ \\
\hline
\end{tabular}

160

Table 2. All these steel double-span assemblies are designed based on the strong column-weak beam seismic design philosophy according to Chinese codes $[15,16]$. Such models have been validated against published test results in [7-9].

As illustrated in Fig. 4 (a), the FE model composed of S4R shell elements was built in a Beam-Joint-Beam (B-J-B) pattern extracted from the damaged bays of the frame. The B-J-B assembly [7] consists of a central column and two connected half-span beams, whose opposite ends are simply supported because of the assumption that the inflection point is located at the mid-span of the original beam members when the central column is removed. Horizontal movements and all rotations are restricted at the top of the central column to simulate the restraints provided by the upper floor system in this scenario. In the pushdown analyses, the quasi-static load $F$ applied to the assembly was assumed to be concentrated at the top of the vertically unsupported central column. A tri-linear stress-strain curve of the steel material, illustrated in Fig. 4(b), was adopted.

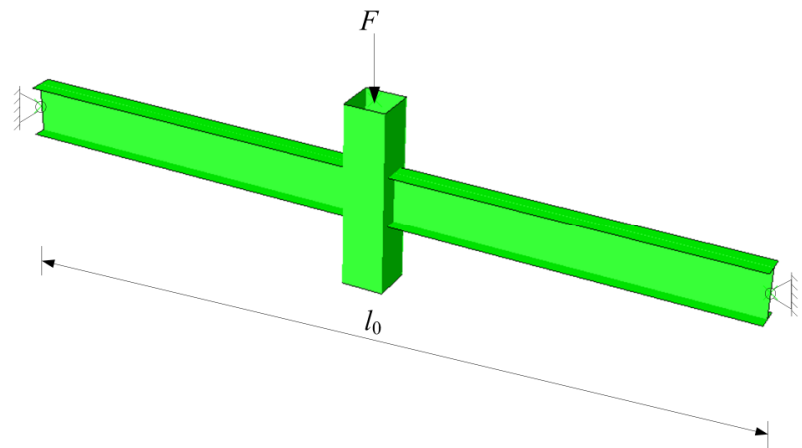

(a) Overview of B-J-B assembly.

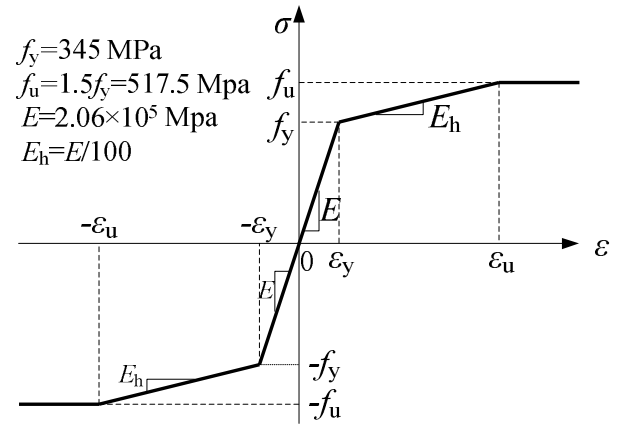

(b) Constitutive model of steel material.

Fig. 4. FE model of steel B-J-B assemblies. 
It can be seen from the analysis results plotted in Fig. 5 that, in contrast to the assemblies having similar span-to-depth ratios plotted in Fig. 3, the assemblies of each set have markedly different responses from each other due to their very different span-to-depth ratios. This outcome is similar for both sets of pushdown analyses irrespective of the beam sections used, clearly demonstrating the principal role of the span-to-depth ratio. The present result is consistent with the finding of Lee et al. [13] that the beam span-to-depth ratio is the underlying factor affecting the response of a frame structure with a removed inner column. with the larger span is more able to develop effective progressive collapse resistance in the event of a column loss, if all the beams have been optimised against plastic hinging

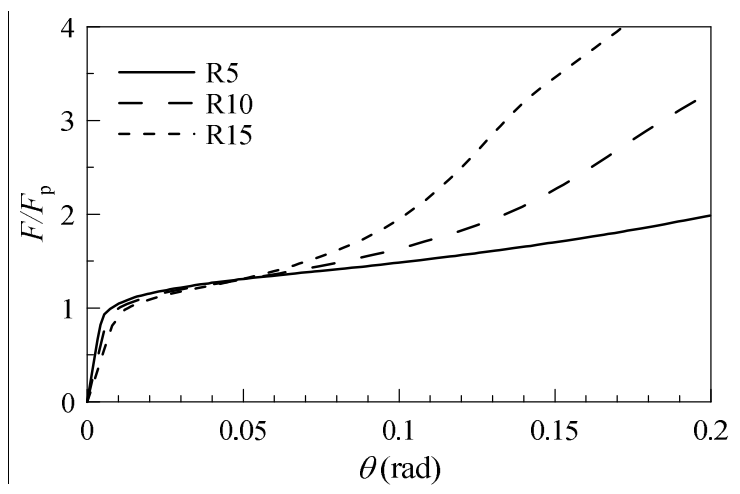

(a) Uniform beam sections $\mathrm{H} 300 \times 150 \times 6 \times 8$.

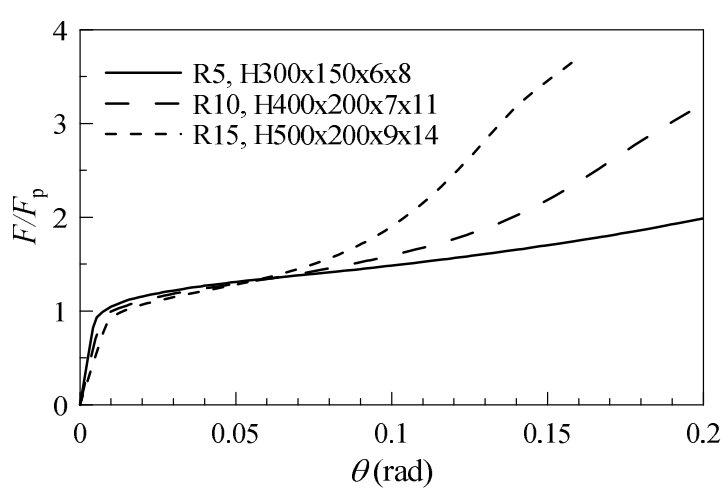

(b) Different beam sections.

Fig. 5. Effect of the beam span-to-depth ratio.

\section{Identification and resolution of the second problem}

Figure 5 shows that there appears to be some differences in the elastic responses 
between the three steel double-span assemblies. In order to accentuate the differences in the development of the catenary mechanism, the chord rotation $\theta$ is normalized over the plastic rotation $\theta_{\mathrm{p}}$, defined as:

$$
\theta_{\mathrm{p}}=\frac{\delta_{\mathrm{p}}}{l_{0} / 2}=\frac{F_{\mathrm{p}}}{K_{\mathrm{e}}} \frac{2}{l_{0}}=\frac{4 W_{\mathrm{p}} f_{\mathrm{y}} / l_{0}}{48 E I_{\mathrm{b}} / l_{0}^{3}} \frac{2}{l_{0}}=\frac{W_{\mathrm{p}} f_{\mathrm{y}} l_{0}}{6 E I_{\mathrm{b}}}
$$

where $K_{\mathrm{e}}$ is the elastic stiffness of a simply supported beam under a concentrated force in the middle, and $I_{\mathrm{b}}$ is the second moment of area of the beam section.

The pushdown analysis results of the steel double-span assemblies in Fig. 5 are re-plotted in Fig. 6 with the horizontal axis being the normalized rotation $\theta / \theta_{\mathrm{p}}$. It can be seen that the different developments of the catenary mechanism under different beam span-to-depth ratios can be investigated better using Fig. 6 .

An equally viable alternative, if not more practical, is to plot the normalized load $F / F_{\mathrm{p}}$ against the normalized displacement $\delta / \delta_{\mathrm{p}}$.

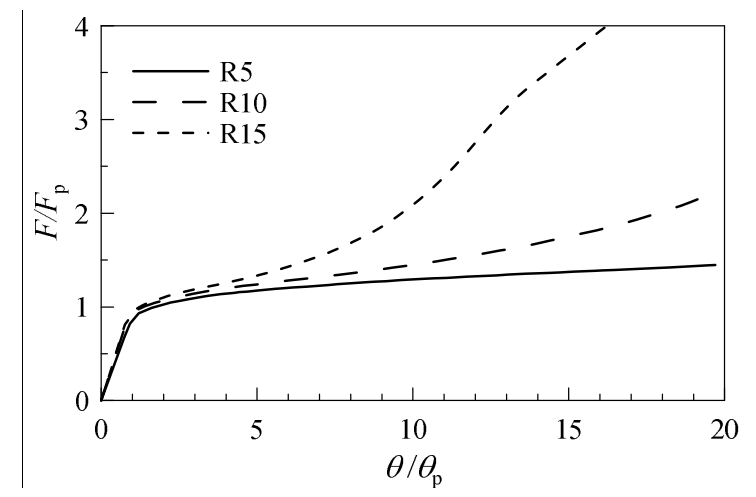

(a) Uniform beam sections $\mathrm{H} 300 \times 150 \times 6 \times 8$.

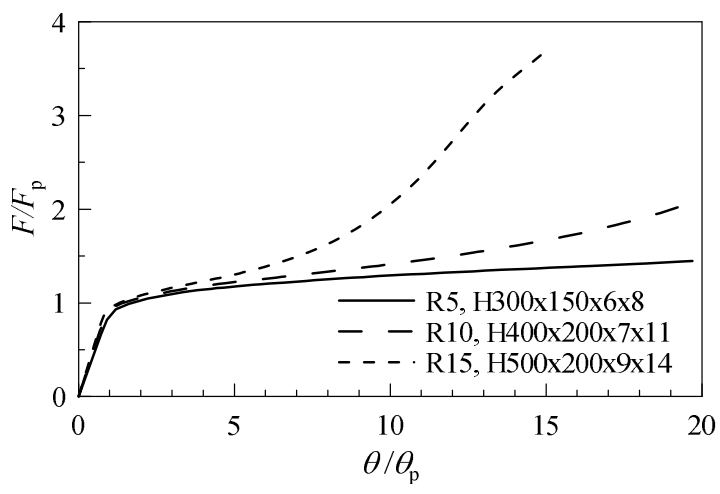

(b) Different beam sections.

Fig. 6. Normalized resistance against normalized rotation.

\section{Conclusions}

It is the beam span-to-depth ratio rather than the beam span itself that affects the progressive collapse resistance of a steel frame undergoing an inner column loss, assuming that the beams have been optimised against plastic hinging under the normal design load or 
the seismic load. The ability of a steel double-span assembly to develop an effective catenary mechanism tends to increase with the span-to-depth ratio, contrary to a recent finding in the literature that the frame having a shorter span has the greater progressive collapse resistance.

205 Normalizing the progressive collapse resistance of various types of steel double-span assemblies against a given uniformly distributed load on the floors can result in ambiguous comparisons, unless the beams have been similarly optimised against plastic hinging under the floor load. The straightforward solution is to normalize the resistance against the plastic hinge load under the column removal scenario, which would give the same comparison outcome as normalizing the resistance against the design floor load for which the beams have been optimised.

212 In order to better compare the ability of various types of steel double-span assemblies to 213 develop an effective catenary mechanism, it is proposed that the normalized resistance is 214 plotted against the beam rotation normalized against the plastic rotation.

215 One implication of the proposed procedure and the finding that steel double-span 216 assemblies having similar span-to-depth ratios exhibit similar responses is that it enables a 217 proper comparison between different types of moment connections as the effects of 218 different beam sections and different spans are filtered out when the same (or similar) 219 span-to-depth ratios are involved. Various types of connections, which may not necessarily suit a given beam section, can still be compared against each other using different beam sections provided the beam span-to-depth ratios are the same. 


\section{Acknowledgments}

The research presented in this technical note was supported by the Natural Science

Foundation of China (NSFC) through No. 51008220 and 51378380. Any opinions,

findings, conclusions, and recommendations expressed in this technical note are those of the authors and do not necessarily reflect the views of the sponsors.

\section{Appendix A.}

As stated in the text, distribution factor $\zeta_{2}$ is not provided by Rezvani et al. [10]. In order to compare the performance of the three frames studied by them on the basis of

Equation (3) and using the load factors $\zeta_{1}$ plotted in Fig. 2, the normalized load $F / F_{\mathrm{p}}$ of each frame is further "normalized" against the quantity $\eta_{1} \eta_{2}$ of Frame 2 ,

$$
\left(\eta_{1}\right)_{2} \eta_{2}=\left(\frac{l_{0}^{3}}{W_{\mathrm{p}}}\right)_{2} \frac{\zeta_{2} q_{0}}{2 f_{\mathrm{y}}}=\frac{l_{02}{ }^{3}}{W_{\mathrm{p} 2}} \frac{\zeta_{2} q_{0}}{2 f_{\mathrm{y}}}
$$

in which the sub-subscript "2" denotes Frame 2 (refer to Table 1), to get a new factor $\zeta_{3}$

where the design parameters $l_{0 i}$ and $W_{\mathrm{p} i}$ as well as the ratios $\alpha_{i}$ and $\beta_{i}$ are listed in Table 1.

\section{References}

[1] Department of Defense: Design of buildings to resist progressive collapse.Washington, D.C.: Department of Defense; 2009 [UFC 4-023-03].

[2] General Service Administration: Progressive collapse analysis and design guidelines for new federal office buildings and major modernization projects. Washington, D.C.: General Service Administration; 2003. 
[4] Yi WJ, He QF, Xiao Y, Kunnath SK. Experimental study on progressive collapse-resistant behavior of reinforced concrete frame structures. ACI Structural Journal. 2008;105(4): 433-439.

[5] Lew HS, Bao YH, Sadek F, Main JA, Pujol S, Sozen MA. An experimental and computational study of reinforced concrete assemblies under a column removal scenario, Rep. No. NIST Technical Note 1720. Maryland: National Institute of Standards and Technology; 2011.

[6] Sadek F, Main JA, Lew HS, Robert SD, Chiarito VP, El-Tawil S. An experimental and computational study of steel moment connections under a column removal scenario. Rep. No. NIST Technical Note 1669. connections under column removal scenario. Journal of Constructional Steel Research. 2013; 88: 244-255. connections. Journal of Constructional Steel Research. 2015; 104: 22-36.

[9] Li L, Wang W, Chen YY, Teh LH. Column-wall failure mode of steel moment connection with inner diaphragm and catenary mechanism. Engineering Structures. 2016; 131: 553-563.

[10] Rezvani FH, Yousefi AM, Ronagh HR. Effect of span length on progressive collapse behaviour of steel moment resisting frames. Structures. 2015;3:81-89.

[11] Weigand JM, Berman JW, Integrity of Steel Single Plate Shear Connections Subjected to Simulated Column Removal. Journal of Structural Engineering, 2014. 140(5): 04013114. temperatures. Journal of Constructional Steel Research. 2016; 124:173-186. 
267 [15] Ministry of Construction of China: Code for design of steel structures. Beijing: China Architecture \& 268 Building Press; 2003 [GB 50017-2003].

269 [16] Ministry of Construction of china: Code for seismic design of buildings. Beijing: China Architecture \&

Building Press; 2010 [GB 50011-2010]. 
272 Fig. 1. Topology of one studied frame having the beam span of $6.0 \mathrm{~m} \mathrm{[10].}$

273 Fig. 2. Pushdown analysis results of frames having different spans [10].

274 Fig. 3. Re-interpreted pushdown analysis results of Rezvani et al. [10].

275 Fig. 4. FE model of B-J-B assemblies.

276 Fig. 5. Effect of the beam span-to-depth ratio.

277 Fig. 6. Normalized resistance against normalized rotation.

278

279

\section{List of tables}

280 Table 1. Primary design parameters of frames in the pushdown analyses of Rezvani et al. [10].

281 Table 2. Beam and column sections of the steel double-span assemblies in the second set. 